\title{
EL BULLYING COMO SUSTITUTO DE LA VIEJA INDISCIPLINA: estrategias frente a la disolución de la autoridad adulta ${ }^{1}$
}

\author{
Mariano Narodowski*
}

\section{Resumen}

Este artículo pretende analizar el fenómeno del denominado bullying en el contexto de los discursos producidos en la investigación científica, en los sistemas educativos y en los medios de comunicación y las redes sociales. En primer lugar, se explican los orígenes del concepto en el marco de la investigación psiquiátrica escandinava para luego comprender las diferencias existentes entre el concepto original y los usos que habitualmente se le dan a la palabra bullying. Seguidamente, se explica la diferencia cuantitativa entre el bullying "de la ciencia" como fenómeno restringido a pocos y muy específicos casos patológicos y el bullying de las escuelas, altamente masificado y difundido por diversas vías. En segundo lugar se intenta comprender cual es la naturaleza de este nuevo fenómeno, construyendo un modelo teórico en el cual concepto de bullying viene a sustituir, en la actualidad del discurso pedagógico, al concepto tradicional de indisciplina escolar. Finalmente, el estudio concluye ubicando al bullying como un concepto de fuerte carácter performativo que da cuenta de la dilución de la autoridad adulta en las instituciones escolares y la consecuente emergencia de nuevas prácticas discursivas que proveen nuevas categorías para abordar los conflictos, sin recurrir a la asimetría propia de la vieja autoridad docente.

Palabras clave: Bullying. Disciplina. Infancia. Adultez. Fin de la infancia.

\section{O BULLYING COMO SUBSTITUTO DA VELHA INDISCIPLINA: estratégias frente à dissolução da autoridade adulta}

\section{Resumo}

Este artigo pretende analisar o fenômeno denominado bullying no contexto dos discursos produzidos na pesquisa científica, nos sistemas educacionais e nos meios de comunicação e redes sociais. Primeiramente são explicadas as origens do conceito no marco da pesquisa psiquiátrica escandinava para então compreender as diferenças existentes entre o conceito original e os usos habitualmente dados à palavra bullying. Posteriormente é explicada a diferença quantitativa entre o bullying "da ciência”, como fenômeno restrito a poucos e específicos casos patológicos, e o bullying das escolas, altamente massificado por diversos modos. Em segundo lugar, o artigo tenta compreender qual é a natureza deste novo fenômeno, construindo um modelo teórico no qual o conceito de bullying substitui, na atualidade do discurso pedagógico, o conceito tradicional de indisciplina escolar. Por fim, o estudo conclui definindo o bullying como um conceito de forte caráter performativo que dá conta da diluição da autoridade adulta nas instituições escolares e da consequente emergência de novas práticas discursivas que provêm novas categorias para abordar os conflitos, sem recorrer à própria assimetria da velha autoridade docente.

Palavras-chave: Bullying. Disciplina. Infância. Maioridade. Fim da infância.

\footnotetext{
${ }^{1}$ Una versión previa de este artículo puede verse en Narodowski, Mariano Sale indisciplina, entra Bullying. Cambios de palabras y disolución de la autoridad adulta, Síntesis Educativa, 15 de febrero de 2012.

* Professor da Universidade Torcuato Di Tella - Argentina. E-mail: mnarodowski@utdt.edu
} 


\title{
BULLYING AS A REPLACEMENT OF THE OLD-FASHIONED INDISCIPLINE: strategies to confront the dissolution of adult authority
}

\begin{abstract}
This article is aimed at analyzing the issue of the so-called bullying in the context of discourses produced in scientific research in educational systems, as well as on the media and the social networks. First of all, the origin of the concept is explained in the framework of Scandinavian psychiatric research with the purpose of understanding the differences between the original concept and the uses generally attributed to the word bullying. Then, there is an explanation on the quantitative difference between the bullying "of science" as a phenomenon restricted to just a few, very specific pathologic cases, and the bullying that takes place in schools, highly expanded and spread through various means. Secondly, there is an attempt to understand the nature of this new phenomenon by building a theoretical model in which the concept of bullying replaces - in the current pedagogical discourse - the traditional concept of school indiscipline. Finally, the study concludes that bullying is a concept with a strong performative character. It is responsible for the dilution of adult authority in schools with the consequent appearance of new discourses, which contribute towards new categories of approaching conflicts without resorting to the asymmetry that characterized the old-fashioned authority of teachers.
\end{abstract}

Keywords: Bullying. Discipline. Childhood. Adulthood. End of childhood.

\section{Todos los caminos conducen al Bullying}

¿Quién no sabe qué es el bullying? Docentes, padres, alumnos, políticos y periodistas han incorporado ese nuevo concepto a su diccionario pedagógico básico acerca de las explicaciones sobre de la vida cotidiana de los chicos, los adolescentes y de las escuelas.

Los programas de televisión y de radio hacen notas especiales sobre bullying. Los noticieros muestran periódicamente los casos más sonados y en la Internet y las redes sociales se reproducen en forma viral sus significados, los que se expanden todo el tiempo. Por ejemplo, al probar con "bullying" o con las más castellanizada "bulling" en el buscador de la red social Twitter se podrá comprobar que se menciona la palabra centenas y hasta miles de veces por hora en todos los países del mundo y en todos los idiomas. Incluso hay decenas de cuentas de Twitter específicamente dedicadas al tema como @TheBullyProject o @StopBullyingNow todas con varios miles de seguidores.

Buscando en Google, "bullying" muestra un total de 71.300 .000 resultados ¿Es mucho? Es difícil encontrar referencias comparativas pero un cotejo simple señala que son bastantes resultados para una palabra relativamente nueva: constituyen casi el 15\% de los resultados que se obtienen con la palabra "education" (580.000.000) ${ }^{2}$.

¿Ahora bien qué significa bullying específicamente? Antes de pasar a una definición

\footnotetext{
${ }^{2}<$ http://www.google.com>. Accedido el 14 de febrero de 2012.
} 
académica un poco más confiable, es necesario partir del reconocimiento de lo que es bullying para los medios de comunicación.

Las diferentes páginas de Internet dedicadas al tema explican que con bullying se trata de dar cuenta de situaciones identificadas como de “abuso”, “acoso” o “intimidación” que se dan en el ámbito escolar, especialmente, aunque no exclusivamente, entre los mismos estudiantes: algunos serán los objetos del acoso, quienes serán denigrados por parte de sus colegas acosadores o "bullies”.

Es interesante señalar que en la opinión pública se ve muchas veces al bullying como el nombre que se le pone a una práctica escolar muy antigua. Suele explicarse que si bien la identificación del bullying se dio en años recientes, muchos de sus divulgadores muestran tradicionales fenómenos de bullying en textos literarios muy anteriores: desde los más antiguos como Oliver Twist de Charles Dickens hasta el más reciente (y genialmente protagonizada la película por Hugh Grant) About a boy del británico Nick Hornby. Para esta visión tan difundida, el bullying existió siempre, pero recién hacia fines del siglo XX el fenómeno adquiere una entidad conceptual precisa (Morrison, 2001).

Sin embargo, una lectura más rigurosa del concepto de bullying, sirve para precisar conceptos y comprender su dinámica teórica como así también rastrear los orígenes y los motivos del enorme impacto que el término tiene en la opinión pública. Según el artículo de Beaty y Alexeyev (2008), el concepto de bullying fue acuñado en el contexto de investigaciones clínicas efectuadas en Noruega a partir de la verificación de tres suicidios por parte de estudiantes adolescentes. Situaciones en aquel momento muy difundidas por la prensa local pero apenas consideradas por los docentes de las escuelas a las que estos jóvenes asistían.

El estudio pionero de Olweus (1991) demostró que aquellos suicidios de estudiantes no fueron más que la consecuencia de una situación concreta de intimidación acaecida en las respectivas instituciones escolares. Este resultado consolidó una línea de investigación académica concentrada en lo que en las lenguas escandinavas de denomina mobbing (en Noruega y Dinamarca) o mobbning (Suecia y Finlandia), términos que se vinculan teóricamente con la identificación psiquiátrica o psicosocial de un conjunto acotado de conductas grupales de agresión a individuos aislados (Olweus, 1991). El término, más tarde, fue virando al bullying y así fue adoptado mundialmente.

Tanto en lo hallado en las investigaciones psiquiátricas originales como en muchos de los estudios ulteriores desplegados sobre una similar base teórica en los últimos veinte años, los resultados demuestran que el bullying es un tipo de síntoma muy focalizado en cuatro 
categorías analíticas rigurosamente establecidas y con una existencia más bien limitada a una población escolar muy minoritaria.

Siguiendo con las conclusiones del muy ilustrativo estudio de Beaty y Alexeyev, para el caso de los países escandinavos originalmente estudiados, el 15\% de la población estudiantil de Noruega aparece involucrada en casos de bullying, pero es el valor más alto para ese grupo de naciones. En relación con otros países, Inglaterra mostraba un 7\% de las población estudiantil muestrada, Australia un 11\%, Estados Unidos 10\% y Canadá registra un escueto aumento intertemporal: 5\% en 1999 y 7\% en 2004 (Beaty y Alexeyev, 2008, pp.2-3). Se trata en todos los casos de estudios científicos con diseños muestrales rigurosos sometidos al arbitraje de pares científicos para su publicación y tomadas en los últimos años del siglo XX y los primeros años del siglo XXI.

Estos datos sorprenden por su pequeño alcance y por sus características contrastan claramente no solamente con el "auge" del concepto de bullying en los medios de comunicación y en las redes sociales sino incluso con muchos de los estudios de victimización de la población estudiantil presuntamente acosada. Para marcar esta divergencia baste decir que en los Estados Unidos, por ejemplo, el 70\% de la población escolar cree haber estado envuelta en un caso de bullying (Bearty y Alexeyev, 2008, p. 1).

¿Cuál es la lógica inmanente a la contradicción entre los relativamente pocos casos de bullying hallados en la investigación científica y la multiplicación de estas situaciones en los estudios de victimización? La respuesta a la pregunta no parece difícil: lo que la investigación científica o académica en el campo psiquiátrico o psicosocial denomina "bullying”, poco o nada parece tener que ver con la denominación difundida en el sistema educativo y a través de los medios, donde el mismo concepto parece aplicarse a muchísimas otras situaciones de la vida cotidiana escolar que para los investigadores no parecen constituir, estrictamente, un caso de bullying.

De esta manera, es necesario distinguir al bullying de la investigación en psicología social y de la psiquiatría, el que le abrió paso al bullying que procesa la televisión, la web e incluso el bullying resignificado en el interior de las escuelas, donde - según diferentes estudios - diversas formas de presión o violencia sobre estudiantes tiende a ser rotulado rápidamente como bullying. Más todavía, se incluyen como prácticas de bullying conductas que anteriormente podían denominarse "racismo”, “clasismo”, “antisemitismo”, “sexismo” discriminación a las personas discapacitadas, etc. mientas la investigación académica viene mostrando una fuerte asociación entre las prácticas denominadas bullying y aquellas que tradicionalmente se catalogaban como discriminación racial y étnica (Scherr y Larson, 2010). 
El estudio de Vaillancourt y otros (2008) es muy interesante al respecto. Ya desde el título del paper los autores se preguntan si los investigadores y los chicos se refieren a lo mismo cuando hablan de bullying. Para responder a la cuestión, los autores dividieron una muestra de 1767 casos de niños y adolescentes de 8 a 18 años en dos grupos. Al primer grupo se le suministró una definición estándar de bullying mientras que al segundo se le preguntó respecto de su propia definición. Los resultados del trabajo mostraron que las definiciones de los chicos estaban muy lejos de las definiciones estandarizadas y muy raramente si quiera consideraban los aspectos prioritarios de las mismas. Por otro lado, y como es lógico, las definiciones -y las preocupaciones- variaban notoriamente con la edad de los alumnos. Además, los chicos a los que se les proveyó de una definición de bullying, tienden a encontrar en sus respectivos entornos más casos de bullying que los chicos a los que no se le proveyó una definición (p.490).

\section{¿Existe el bullying?}

Frente a este cúmulo de evidencias que marcan importantes diferencias entre el diagnóstico de una parte de de la comunidad científica y el diagnóstico construido por parte de la opinión pública y de los propios actores del bullying, la pregunta que se impone es ¿Existe el bullying? $\mathrm{O}$ acaso se trata solamente de una suerte de redenominación con un término específico, en lengua inglesa y posiblemente más sofisticado, de prácticas escolares que tradicionalmente fueron condenadas en las instituciones escolares aunque caracterizadas, históricamente con el concepto de “indisciplina escolar”.

La respuesta que es posible construir en función de lo que hasta fue desarrollado merece problematizar la pregunta. Por un lado, no caben dudas que la investigación psicológica y psiquiátrica ha caracterizado un síntoma determinado, muy específico y focalizado a cierto tipo de agresiones acaecidas entre estudiantes en ocasión de asistir a las instituciones escolares. Es innegable que el bullying es un objeto de estudio científico, que seguramente presentará sus controversias epistemológicas y teóricas que interpretan la evidencia obtenida. Hasta es posible advertir ciertos sesgos ideológicos en algunas de las caracterizaciones académicas del bullying. Pero más allá de controversias teóricas existentes y de críticas ideológicas posibles, la identificación de bullying entre estos investigadores se corresponde con situaciones muy acotadas, muy específicas y de abordaje clínico alejado a la comprensión del lego en la materia.

Por otro lado, parece evidente la existencia de un uso más fuerte del término bullying 
por parte de la opinión pública. En los medios, en las redes sociales y en las escuelas se denomina bullying a conductas que de acuerdo a la literatura académica no serían científicamente bullying, pero... ¿¿Es eso tan importante? El bullying se ubica en el universo conceptual de las escuelas y los medios en un lugar central operando como un identificador de buena parte las acciones percibidas como agresivas o violentas que acontecen en las escuelas entre estudiantes y con otros actores de las instituciones educacionales. Más allá de la posible inconsistencia científica en la caracterización, el concepto bullying presenta una alta performatividad en términos comunicacionales y eso es lo que importa: como se ha visto, se trata de un concepto lave, cada vez más utilizado para aludir a la convivencia y al conflicto en las escuelas.

¿Se podría afirmar, por lo tanto, que el bullying no existe? Se podría concluir que la mayoría de las situaciones así identificadas no son realmente bullying? Si bien desde un punto de vista psiquiátrico tal vez pueda arribarse a esa constatación, desde el interés por comprender a las escuelas, una inferencia de ese tipo no guarda el menor interés. En términos foucaultianos operaría como una hipótesis represiva que apenas constata una ausencia sin comprender la estrategia discursiva en la cual está inscripta (Foucault, 2006). El bullying existe en todos los casos en los que así se lo enuncia en términos de una determinada construcción conceptual, muchas veces implícita, que permite dotar de sentido un conjunto amplio de prácticas escolares.

Si se acepta, entonces, el mero valor performativo del término, abstrayéndose de toda controversia epistemológica, la pregunta que sigue es ¿por qué bullying?

\section{Adultos se buscan}

Ya hace tiempo que algunos estudios vienen mostrado que muchas de las prácticas culturales que daban sustento al ejerció adulto de la modernidad han sido sustituidas por otras prácticas y otros parámetros culturales (Postman, 1982; Baquero y Narodowski, 1993; Narodowski, 2011).

Si bien algunos de las hipótesis y de las evidencias aportadas por estas investigaciones son materia de controversia (Buckingham, 2000) es posible al menos cuestionar que la experiencia adulta pierde preponderancia Siguiendo algunas líneas de pensamiento provocativamente anunciadas por Gilles Lipovetsky (1991), es posible afirmar que, actualmente, la vejez e incluso la adultez parecen haber pasado a un o segundo plano siendo sustituida por la exaltación de lo nuevo, de lo juvenil, e incluso de lo infantil. 
Al contrario de las culturas que Margaret Mead (1970) denominaba posfigurativas (en la que los cambios lentos en la tecnología , la producción y la sociedad se modifican lentamente y son los viejos los que hacen valer el gobierno de su experiencia), los cambios acelerados en el escenario social son los que establecen una forma diferente en el intercambio intergeneracional: serán ahora los niños y los jóvenes los portadores de bienes culturales valiosos ya que su dominio de acciones y discursos fue configurado en la nueva situación, lo que Mead denominó culturas “prefigurativas” (Mead, 1970; Narodowski, 1999 y 2012). Esta cultura de cambios constantes y abruptos, valora a las nuevas experiencias y reivindica esas infancias y adolescencias antes subestimadas: solamente los individuos formados en la turbulencia de los cambios son quienes interactúan eficazmente en ellos. Quienes pertenecen a generaciones anteriores, no tienen más que ajustarse a lo nuevo siguiendo, paradojalmente, el sendero abierto por jóvenes: la ecuación parece haberse invertido y con ella la lógica asimétrica que la sustentaba. (Narodowski, 2012)

La percepción posfigurativa de niño dependiente, obediente y heterónomo elaborada en los últimos siglos (Aries, 1973; Narodowski, 2001) es cuestionada por la ponderación de lo joven Ser niño o adolescente ya no implica, como antaño, una sencilla carencia superable por la acción educativa adulta Al contrario, los adultos actuales intentan lograr una fisonomía exterior, un lenguaje, unos gustos estéticos asimilables a los de los más jóvenes. Esa es su forma de seguir vigentes. (Lipovetsky, 1991)

Las consecuencias de la acción del mundo adulto ya no parecen concitar un valor que genere legitimidad y respeto en si mismo. La tendencia de nuestras sociedades contemporáneas parece ser la creciente desjerarquización: una suerte de horizontalización que implica el opuesto de las jerarquías asimétricas de antaño (Sennett, 2003). En este panorama, los agentes sociales son reconocidos como portadores de saberes legítimos posibles de ser intercambiados por medio de una suerte de aplanamiento desjerarquizado de las relaciones sociales. Donde había un nudo asimétrico puede encontrarse pura intercambiabilidad. Donde las jerarquías de edad y de conocimientos emplazaban al otro al lugar de la dependencia y la heteronomía (a la infantilización) hoy reina la regulación de una suerte de simetría que, aunque sin saberlo, proclama una revalorización de relaciones prácticamente sindiásmicas. En ese sentido, las equivalencias se han universalizado y la autoridad ya no lo es por la marca de su origen sino, en el mejor de los casos, habrá de legitimarse por la significatividad que encierra su ejercicio: una legitimidad siempre contingente, situacional y pasajera (Narodowski, 2005; 2012)

Es evidente que frente a esta retirada del cuidado adulto del escenario escolar y al 
subsecuente declive de la "disciplina escolar" como elemento ordenador de la vida cotidiana en las instituciones, el fantasma de la desprotección y la inseguridad crece entre muchos alumnos quienes, según la evidencia arriba citada, en altos porcentajes se sienten indefensos respecto de lo que otros pares efectivamente les hacen o les podrían llegar a hacer para perjudicarlos.

Por eso, el concepto de bullying encaja perfectamente en esta escena de licuación posmoderna de la autoridad adulta como un concepto multiuso que por su vaguedad parece ajustarse a la perfección con el sentido común de nuestra época: el bullying no precisa siquiera -al menos no necesariamente-, de la agresión física directa: basta con la insinuación de la intimidación o del acoso (en realidad basta con que alguien se sienta intimidado o acosado) para denunciar una conducta de tipo bullie. La caracterización light que hace el bullying de las conductas ajenas se engarza con los sentimientos de inseguridad propios de las grandes ciudades de nuestro capitalismo tardío. (Baumann, 2007)

Más todavía, este puede ser el motivo por el que el bullying ha extendido sus dominios conceptuales por fuera del grupo de pares en la escuela y ya se consideran, por ejemplo, docentes bullis e incluso, por fuera de la escuela. Ya hay bullying también, por ejemplo, en el lugar de trabajo no escolar

Además, el anti-bullying congrega el trabajo conjunto y la solidaridad para combatirlo. Mientras la indisciplina generaba revueltas y deseos de emancipación, en las escuelas, en los medios $\mathrm{y}$ en las redes sociales se articulan proyectos conjuntos para identificar a los agresores, prevenir las agresiones, ayudar a confortar a las víctimas y denunciar toda posibilidad de conducta que perjudique a otros. En Youtube pueden verse cientos de videos de todo el mundo en los que se muestran organizaciones y comunidades anti bullying. Y hasta la MTV le dedicó una campaña. ${ }^{3}$

Sin embargo, la magnitud de esta eficacia viral del concepto de bullying no puede explicarse solamente por el hecho de que su amplitud y su flexibilidad hermenéutica sean acordes a la época. Esta concordancia con la época se termina de explicar, a su vez, por un fenómeno clave que hasta ahora no ha aparecido ni en las explicaciones científicas ni en las versiones de la opinión pública y la Internet: el adulto; en este caso, el docente.

Es evidente que el bullying es cosa de pares y parece sucederse cotidianamente - $\mathrm{o}$ al menos eso es lo que se denuncia continuamente- sino con la anuencia pasiva, al menos con la indolencia, la ignorancia y, hasta se podría arriesgar, la impotencia por parte de los adultos.

\footnotetext{
${ }^{3}<$ http://www.youtube.com/watch?v=D3KsGTIeO7A>. Accedido el 13 de febrero de 2012.
} 
Esto se observa claramente en la revisión de la literatura científica efectuada por parte de Beaty y Alexeyev (2008) ya antes citada: según todos los estudios reseñados los docentes son los menos advertidos respecto de los procesos de bullying (p.6). Irónicamente, algunos estudios que examinan las diferentes posibilidades de combatir el bullying proponen recurrir a la importancia de la acción del docente...

Este dato es significativo: en las estrategias de análisis e incluso en las de intervención antibullying, el docente aparece al margen del bullying como si no fuese responsable de su existencia e incluso hasta como un actor que usualmente no necesariamente está dispuesto a la luchar por su mitigación: a modo de ejemplo, en un diario de Buenos Aires que comenta la actitud de los docentes frente a la discriminación y el bullying, puede leerse "La prueba de que la discriminación y el acoso en las aulas es un tema que se pretende esquivar está en que la investigadora, para su investigación [sobre bullying], sólo logró que le respondieran unas pocas escuelas, muchas menos de las que esperaba” 4

. Este punto es central para la interpretación que aquí se está desarrollando: el bullying de las redes sociales, de las escuelas, de los medios (es decir, el bullying de la realidad de la vida cotidiana y no el de las investigaciones psicológicas) parece obedecer a un corrimiento del lugar del docente como lugar de la autoridad adulta (Narodowski, 1999) y la a desaparición de la idea tradicional de “indisciplina escolar”:

Como ya hemos analizado largamente en estudios anteriores (Narodowski, 2001 y 2005), este concepto tenía dos definiciones posibles: por un lado se presentaba como el efecto observable y clasificable (por parte del docente) de las conductas de alumnos que debían ser enderezadas. Por otro lado, era la consecuencia de la impericia o la incapacidad de un mal docente. En ambos casos -sea por un accionar eficaz de un educador, sea por su desidia o su ineficacia- el adulto era la pieza clave en el sostenimiento del orden escolar

Al contrario, el bullying expresa la caducidad del accionar adulto y representa la generalización de las conductas reprochables que emergen y se reproducen frente a la incapacidad adulta de evitarlas o contrarrestarlas.

Mientras en la vieja institución escolar regida por la ley adulta las conductas consideradas violentas de los chicos y los adolescentes habrían de ser corregidas (“educadas”) por los adulto responsables, en las actuales escuelas de autoridad adulta diluida (o virtualmente disuelta) la aparición de estas prácticas suele dispensar a los docentes para su existencia y, lo que es más relevante, también para su eliminación: la autoridad adulta del

\footnotetext{
4 “El silencio como cómplice” en Clarín, 8 de mayo de 2012.
} 
docente aparece desjerarquizada en un concierto variopinto de voces diversas que se apenas oyen en los consejo escolares, en las comunidades, en los grupos terapéuticos, en algunas campañas publicitarias. En la campaña antibullying de la MTV la autoridad adulta ni tan siquiera es mencionada en todo lo largo del video: un mundo sin adultos, por fin.

Así, una nueva mirada sobre los mismos ejemplos literarios que brindan los ya citados difusores del concepto amplio bullying para afirmar que "bullying hubo siempre” parecen darnos la razón bajo esta nueva luz. Oliver Twist es perseguido y acosado por sus pares; es cierto. Pero la persecución y el acoso cesan una vez que la institución adulta se hace cargo del buen Oliver: el pretendido "bullying” desaparece cuando la autoridad adulta ocupa en la escuela o en la familia un lugar de protección y responsabilidad por las conductas infantiles, Esas conductas disruptivas no merecían llamarse, entonces, bullying en su sentido actual: eran conflictos que se esfumaban, o al menos se apaciguaban, con la sola presencia adulta.

Algo parecido ocurre con About a boy, una novela bien de estos tiempos, igualmente inglesa pero alejada de las prácticas victorianas y decimonónicas que narra Dickens. En la novela, el chico acosado aprende del adulto las herramientas para encontrar su lugar y así poder defenderse de otros chicos: es el mundo adulto el que lo va a guiar, en el caso de Will (el adulto de la novela) organizando y ordenando las posibilidades concretas de respuesta del chico acosado. Will lo protege, en este caso, aconsejándolo para que aprenda a hacerse invisible o "Podes no conseguir ser invisible, pero podemos mezclarte con la multitud" 5 .

En las viejas épocas, la indisciplina evocaba a la autoridad y la autoridad evocaba, a su vez, el ser adulto: todo demasiado pesado y un tanto demodée. La ausencia de adulto desprotege a la infancia y a la adolescencia y esto naturalmente genera un escenario de inseguridad, de temor. No hay indisciplina ya que no se trata de situaciones que a los adultos se les han ido de las manos y está en esas manos corregir el rumbo: directamente no hay manos adultas.

El bullying es un concepto bien fácil de manejar en un contexto que la autoridad adulta no se ejerce pero ya ni se reclama. Un concepto flexible, amplio, liviano, que permite intentar resolver conflictos sabiendo que el docente en tanto adulto ocupando un lugar de saber es algo que no necesariamente habrá de ocurrir.

\footnotetext{
${ }^{5}$ Para un brillante análisis pedagógico de About a boy recomiendo fuertemente la lectura de un excelente trabajo de Estanislao Antelo ¿No hables con extraños? en <http://www.estanislaoantelo.com.ar/files/no-hables-conextranos.pdf $>$. Accedido el 13 de febrero de 2012.
} 


\section{Referências}

ARIÈS, Philippe L'enfant et la vie familiale sous l'Ancien Régime, Paris; Seuil, 1973.

BAUMANN, Zygmunt Liquid times. Living in an Age of Uncertaity, Cambridge: Polity Pres, 2007.

BEATY, Lee, Alexeyev, Erick "The Problem of School Bullies: What the Research Tell Us“ Adolescence, 43, Spring 2008.

Buckingham, David After the death of childhood: Growing up in the age of electronic media, Malden: Polity Press, 2000.

Foucault, Michel, Historia de la sexualidad. I La voluntad de saber, Madrid, Siglo XX1, 2006.

Lipovetsky, Gilles L'empire de l'éphémère: la mode et son destin dans les sociétés modernes, Paris: Gallimard, 1991.

Mead, Margaret Culture and commitment: a study of the generation gap, New York: Natural History Press, 1970.

Morrison, Brenda Restorative justice and school violence: Building theory and practice Paper presented at the International Conference on Violence in Schools and Public Policies, Palais de l’UNESCO, Paris, 2001.

Narodowski, Mariano y Ricardo Baquero, “¿Existe la infancia? En Revista del Instituto de Investigaciones en Ciencias de la Educación, Nro. 11, 1994.

Narodowski, Mariano, Después de clase. Desencantos y desafíos de la escuela actual, Buenos Aires, Novedades Educativas, 1999.

Narodowski, Mariano Infância e poder: conformação da pedagogia moderna, São Paulo: Universidade de São Francisco, 2001.

Narodowski, Mariano “Destinos de la infancia: hiper y desrealización” Arellano Dique, Antonio (coord.) La educación en tiemps débiles e inciertos, Madrid: Antropohos, 2005. Narodowski, Mariano, "No es fácil ser adulto. Asimetrías y equivalencias en las nuevas infancias y adolescencias”, Educación y pedagogía, nro 60, 2011.

Narodowski, Mariano Looking for Asymmetries: A theoretical approach to the feeling of nostalgia in modern childhood as well as adulthood, paper presented to II PLACIM Seminar, University of Reading, 2012.

Postman, Neill The disappearance of childhood, New York: Vintage Books, 1994 Scherr, Tracey G.; Larson, Jim "Bullying dynamics associated with race, ethnicity, and immigration status” Jimerson, Shane R.; Swearer, Susan M.; Espelage, Dorothy L. (Eds.)Handbook of bullying in schools: An international perspective, )New York, Routledge/Taylor \& Francis, 2010. 
Sennett, Richard Respect in an Age of Inequality, New York: Norton, 2003.

Vaillancourt, T., McDougall, P., Hymel, S., Krygsman, A., Miller, J., Stiver, K., \& Davis, C. (2008). Bullying: Are researchers and children/youth talking about the same thing?. International Journal Of Behavioral Development, 32(6). 